\title{
Dyslipidemia in People Living with HIV on Anti-Retroviral Treatment: Case of the Ambulatory Treatment Center (ATC) of the Sylvanus Olympio University Hospital of Lome
}

\author{
Abdou Razak Moukaila1,2* (D), Lidaw Déassoua Bawe², Edem Komi Mossi', \\ Akessiwe Akouda Patassi ${ }^{2}$, Yawovi Mawufemo Tsevi ${ }^{3}$, Komi Dzidzonu Nemi ${ }^{1}$, \\ Laconi Yéba Kaaga1, Rissikatou Ewetola1, Agbeko Kodjo Djagadou1, Abago Balaka1, \\ Majesté Ihou Wateba' ${ }^{2}$ Awalou Mohaman Djibril ${ }^{1}$
}

\begin{abstract}
${ }^{1}$ Department of Internal Medicine, University Hospital Sylvanus Olympio Lomé, University of Lomé, Lomé, Togo ${ }^{2}$ Departement of Infectious and Tropical Diseases, University Hospital Sylvanus Olympio of Lomé, University of Lomé, Lomé, Togo

${ }^{3}$ Department of Nephrology and Hemodialysis, University Hospital Sylvanus Olympio of Lomé, University of Lomé, Lomé, Togo Email: *moukaila.razak@gmail.com
\end{abstract}

How to cite this paper: Moukaila, A.R., Bawe, L.D., Mossi, E.K., Patassi, A.A., Tsevi, Y.M., Nemi, K.D., Kaaga, L.Y., Ewetola, R., Djagadou, A.K., Balaka, A., Wateba, M.I. and Djibril, A.M. (2019) Dyslipidemia in People Living with HIV on Anti-Retroviral Treatment: Case of the Ambulatory Treatment Center (ATC) of the Sylvanus Olympio University Hospital of Lome. Open Journal of Internal Medicine, 9, 141-157. https://doi.org/10.4236/ojim.2019.94019

Received: November 1, 2019

Accepted: December 9, 2019

Published: December 12, 2019

Copyright $\odot 2019$ by author(s) and Scientific Research Publishing Inc. This work is licensed under the Creative Commons Attribution International License (CC BY 4.0).

http://creativecommons.org/licenses/by/4.0/ (c) (i) Open Access

\begin{abstract}
Introduction: Dyslipidemia is a significant cardiovascular risk factor in patients living with HIV (PLWHIV). Few data are available in Togo. Objective: The purpose of this study is to assess the prevalence of dyslipidemia and associated factors in PLWHIV on Highly Active Antiretroviral Therapy (HAART). Methods: This is a descriptive and analytical cross-sectional study of patients followed at the Sylvanus Olympio University Hospital's infectious diseases department for six months. The study population consisted of any PLWHIV patient on HAART over 18 years of age who had been regularly monitored and had a serum lipid fraction assay. Results: Two hundred and eighty-four patients were included. $75.4 \%$ were women. The median age was 46 years (IQR: 39 - 52) and the median CD4 count was $461 \mathrm{cel} / \mathrm{U} 1$ (IQR: 330 - 607). Eighty-three percent of the patients had suppressed viral load. The median duration of follow-up under antiretroviral treatment antiretroviral treatment was 4.18 years (IQR: 2 - 7). The prevalence of dyslipidemia was $72.5 \%$. HDL hypocholesterolemia (HDL-c $<40 \mathrm{mg} / \mathrm{dl}$ ) was the most represented dyslipidemia in $49.6 \%$. Body mass index, past treated tuberculosis, HAART regimen substitution, abdominal obesity, past smoking and being exposed to Nucleoside reverse transcriptase inhibitors (NRITs) were found to be factors associated to dyslipidemia. Conclusion: Our study revealed a high prevalence of
\end{abstract}


dyslipidemia in patients on HAART as well as associated factors. To this end, it is necessary to insist on screening for dyslipidemia before and after initiation of HAART in order to prevent the occurrence of cardiovascular events in PLWHIV.

\section{Keywords}

Dyslipidemia, HIV/AIDS, Togo, HAART

\section{Introduction}

The number of people living with HIV (PLWHIV) in 2017 was estimated to 36.9 million worldwide, of which 6.1 million live in West and Central Africa [1]. Increased access to antiretroviral treatment (HAART) has improved the care of PLWHIV.

The frequency of opportunistic infections has significantly decreased, improving patients' life expectancy. HIV infection has now become a chronic disease.

PLWHIV are now facing non-transmissible diseases linked to metabolic disorders such as dyslipidemia [2]. Dyslipidemia that leads to atherosclerosis [3] is recognized as risk factor for cardiovascular events alone or as part of a metabolic syndrome. PLWHIV are reported to be at greater risk of cardiovascular events than the general population [4].

According to some studies, depending on the current antiretroviral regimen, the prevalence of total hypercholesterolemia (HCT) in PLWHIV can reach 51\% [5]. For hypertriglyceridemia (HTG), prevalences of up to 55\% have been reported [6] while for HDL hypocholesterolemia $(\mathrm{HCH})$ and for LDL hypercholesterolemia (HCL) prevalences of up to $43 \%$ and $47 \%$, respectively, have been reported [6] [7].

Few data on dyslipidemia remain available in African countries compared to developed countries.

Togo is a West African country with an estimated population of 7.798 million in 2017. The average prevalence of HIV/AIDS in Togo is estimated in 2017 in the general population aged $15-49$ to $2.1 \%$ [8].

The objective of our study is to study the prevalence of dyslipidemia in PLWHIV patients on HAART as well as associated risk factors in order to provide useful data for the care of these patients.

\section{Patients and Methods}

\subsection{Presentation of the Study Site}

Our study took place at the Ambulatory Treatment Center (ATC) of the Infectious Diseases Department of the Sylvanus Olympio University Hospital of Lomé (CHU-SO). This is the reference service for the care of PLWHIV in Togo. 
This service has an active line of 3528 patients, $70 \%$ of whom are women.

\subsection{Type and Period of Study}

We conducted a descriptive and analytical cross-sectional study on patients received in routine follow-up consultations during the period of July 1st to December 31st, 2018, a six months period.

\subsection{Study Population}

The study population consisted of all PLWHA on HAART over 18 years of age who had been regularly monitored for at least six months at the CTA of the CHU SO, having not missed any follow-up appointments in the six months preceding the day of their consultation. The patient was required to have the results of his or her follow-up blood test up to three months old, consisting of a serum total cholesterol (TC), triglycerides (TG), HDL-cholesterol (HDL-c), LDL-Cholesterol (LDL-c), CD4 (TxCD4), and viral load (CV).

Any patient with a situation that could lead to an increase in abdominal volume and distort waist measurement (pregnant woman, liver pathology with ascites) or taking a treatment likely to disturb the lipid balance as a treatment with corticosteroid or lipid-lowering agent were excluded.

\subsection{Sampling Method}

We randomly selected for our study a sample of 284 patients who met the inclusion criteria.

\subsection{Collection of Data}

A data collection sheet was designed and used as a basis for data collection. Patients were informed in advance of the details of the data collection process. The data collected were: 1) socio-demographic data, age, sex; 2) history of pre-existing high blood pressure (hypertension) or ongoing antihypertensive treatment, the existence of known diabetes under treatment or not, a history of treated tuberculosis, alcohol consumption, active smoking 3 ) the history of HIV, namely the WHO clinical stage at initiation of treatment, the length of time spent on HAART, the CD4 count at initiation, the notion of substitution of combinations during HAART, the current ARV protocol; 4) anthropometric data such as weight, height, body mass index, waist circumference; 5) data from analyses of TxCD4 monitoring, CT, TG, HDL-c assays. LDL-c was calculated from the Friedwald formula according to the formula: $L D L-c=C T-(H D L-c+T G / 5)$.

\subsection{Data Sources}

Age, sex, notions of hypertension and diabetes, history of HIV, were collected by interview and via the care record.

The weight was measured using a weighting scale. The height was measured using a measuring tape. The body mass index (BMI) was calculated using the ra- 
tio of weight-to-height squared. A BMI between 25 and $29.9 \mathrm{kgs} / \mathrm{m}^{2}$ defined overweight and a BMI greater than $30 \mathrm{kgs} / \mathrm{m}^{2}$ defined obesity. High waist circumference has been defined according to the criteria of the International Diabetes Federation (waist circumference greater than or equal to $94 \mathrm{~cm}$ in men and greater than $80 \mathrm{~cm}$ in women).

Every six months, each patient is invited to carry out an immunological, biochemical checkup and every year a dosage of the viral load. Only the immunological and virological assessment is subsidized. We therefore use the results of these analyzes to collect informations.

The presence of an abnormality in the lipid checkup was described as dyslipidemia according to the criteria of the United State National Cholesterol Education Program, Adult Treatment Panel III (USNCEP-ATP III) which are: HCT if total cholesterol levels are greater than or equal to $200 \mathrm{mg} / \mathrm{dl}$, HTG if triglyceridemia is greater than or equal to $150 \mathrm{mg} / \mathrm{dl}, \mathrm{HCH}$ if HDL cholesterol levels are less than $50 \mathrm{mg} / \mathrm{dl}$ in women and less than $40 \mathrm{mg} / \mathrm{dl}$ in men, HCL if LDL cholesterol levels are greater than or equal to $130 \mathrm{mg} / \mathrm{dl}$. The atherogenicity index was evaluated on the basis of the CT/HDL ratios, which is a revealing indicator of arterial and especially coronary risk. If the CT/HDL ratio is higher than 5 the atherogenic risk is statistically significant.

\subsection{Statistical Analysis of Data}

All data were entered into an input mask developed in the epi data version 3.1 software and then analyzed using the IBM SPSS Statistics 20 statistical software.

The descriptive analysis included means and standard deviations, medians and interquartile range for quantitative variables. Percentages were used for qualitative data.

The differences between the means and percentages were assessed using the Student's t-test for quantitative variables, and the chi-square test for qualitative variables.

The test results were considered statistically significant if the $p$-value $<0.05$.

\subsection{Ethical Considerations}

The authorization of the head of Infectious Diseases Department in charge of the Ambulatory Treatment Center for HIV-infected persons has been obtained. The written consent of patients was obtained after an informed explanation of the objectives of the study. Anonymity and confidentiality of the results were respected.

\section{Results}

\subsection{General Characteristics of the Study Population}

A total of 284 patients were enrolled in our study. The female sex was predominant with a proportion of $75.4 \%$ (Table 1). The median age was 46 years (IQR: $39-52)$.

The 30 to 49 age group was predominant in $61.6 \%$. 
Table 1. Characteristics of $284 \mathrm{HIV}$ infected subjects on ARV medications.

\begin{tabular}{|c|c|}
\hline Characteristics & $\mathrm{N}(\%)$ \\
\hline \multicolumn{2}{|l|}{ Gender } \\
\hline Male & $70(24.6)$ \\
\hline Female & $214(75.4)$ \\
\hline Total & $284(100)$ \\
\hline \multicolumn{2}{|l|}{ Age (Years) } \\
\hline $18-29$ & $9(3.2)$ \\
\hline $30-39$ & $66(23.2)$ \\
\hline $40-49$ & $109(38.4)$ \\
\hline $50-59$ & $64(22.5)$ \\
\hline $60+$ & $36(12.7)$ \\
\hline Total & $284(100)$ \\
\hline \multicolumn{2}{|l|}{ Hypertension* } \\
\hline Yes & $37(13)$ \\
\hline No & $247(87)$ \\
\hline Total & $284(100)$ \\
\hline \multicolumn{2}{|l|}{ Diabetes mellitus } \\
\hline Yes & $7(2.5)$ \\
\hline No & $277(97.5)$ \\
\hline Total & $284(100)$ \\
\hline \multicolumn{2}{|c|}{ Past treated tuberculosis } \\
\hline Yes & $25(8.8)$ \\
\hline No & $259(91.2)$ \\
\hline Total & $284(100)$ \\
\hline \multicolumn{2}{|l|}{ Past smoking } \\
\hline Yes & $11(3.9)$ \\
\hline No & $273(96.1)$ \\
\hline Total & $284(100.0)$ \\
\hline \multicolumn{2}{|c|}{ WHO Clinic State at the HAART initiation } \\
\hline Stade 1 & $43(15.1)$ \\
\hline Stade 2 & $93(32.7)$ \\
\hline Stade 3 & $87(30.6)$ \\
\hline Stade 4 & $61(21.5)$ \\
\hline Total & $284(100.0)$ \\
\hline \multicolumn{2}{|l|}{ BMI $\left(\mathrm{kg} / \mathrm{m}^{2}\right)$} \\
\hline$<18$ & $27(9.5)$ \\
\hline $18-24.9$ & $141(49.6)$ \\
\hline $25-29.9$ & $83(29.2)$ \\
\hline $30+$ & $33(11.6)$ \\
\hline
\end{tabular}




\begin{tabular}{cc}
\hline Total & $284(100.0)$ \\
Abdominal obesity & \\
Yes & $96(55.8)$ \\
No & $76(44.2)$ \\
Total & $172(100)$ \\
\hline
\end{tabular}

*Blood Pressure $\geq 140 / 90$ (mmHg); WHO: World Health Organization; HAART: Highly Active Antiretroviral Therapy; BMI: Body Mass Index.

Eight point eight percent of the patients in our sample had a past history of treated tuberculosis (TB). Two point five percent of patients were known to be diabetic and 13\% were known hypertensives. Thirteen point one percent of the patients in our series reported being alcohol consumers. Three point nine percent of the subjects had a smoking history. Fifty-seven percent of the subjects had already seen their HAART combination substituted at least once. Eighty-two point seven percent of the patients in our sample were on 1st line HAART and $17.3 \%$ on 2 nd line HAART. At the initiation of treatment, $63.3 \%$ of patients were in WHO clinical stages 2 and 3. The median duration under ART was 4.18 years (IQR: 2 - 7). Fifty-nine point three percent of the patients in our sample had been under HAART for less than five years.

The median body mass index was $23.80 \mathrm{~kg} / \mathrm{m}^{2}$ (IQR: 21.05 - 27.05). Forty point eight percent of patients in our study had BMI of $25 \mathrm{~kg} / \mathrm{m}^{2}$ or greater.

The average waist circumference was $86 \mathrm{~cm}( \pm 10.5)$. High waist circumference defined abdominal obesity was present in $55.8 \%$ of patients.

The median duration of follow-up under antiretroviral treatment antiretroviral treatment was 4.18 years (IQR: 2 - 7). With Lamivudine (3TC) as the common molecule for all combinations, the first line combined two of three nucleotide reverse transcriptase inhibitors (NRTI), Tenofovir (TDF), Zidovudine (AZT) or Abacavir $(\mathrm{ABC})$ with one non-nucleotide reverse transcriptase (NNRTI) either Efavirenz (EFV) or Nevirapine (NVP). In second-line combinations, NNRTI was replaced by a protease inhibitor (PI), either Ritonavir-boosted Atazanavir (ATV) or Ritonavir-boosted Lopinavir (LOP).

The distribution of subjects by NRTI exposure was 90.5\% under TDF, 6.7\% under ABC, and 2.8\% under AZT. For those exposed to NNRTIs, $98.3 \%$ of subjects were on EFV and $1.7 \%$ on NEV. For those who were on PIs, $89.8 \%$ were on ATVs and $10.2 \%$ on LOPs.

The median CD4 count was 461 cel/U1 (IQR: 330 - 607). Eighty-three percent of the patients had suppressed viral load.

\subsection{Lipid Profiles of Patients}

Dyslipidemia were found in $72.5 \%$ of cases. The prevalence of each type of dyslipidemia was $49.6 \%$ for $\mathrm{HCH}, 32.7 \%$ for $\mathrm{HCL}, 30.6 \%$ for $\mathrm{HCT}$ and $10.9 \%$ for HTG (Figure 1). Fourteen point height percent of the subjects in our study had a CT/HDL ratio greater than 5 . 


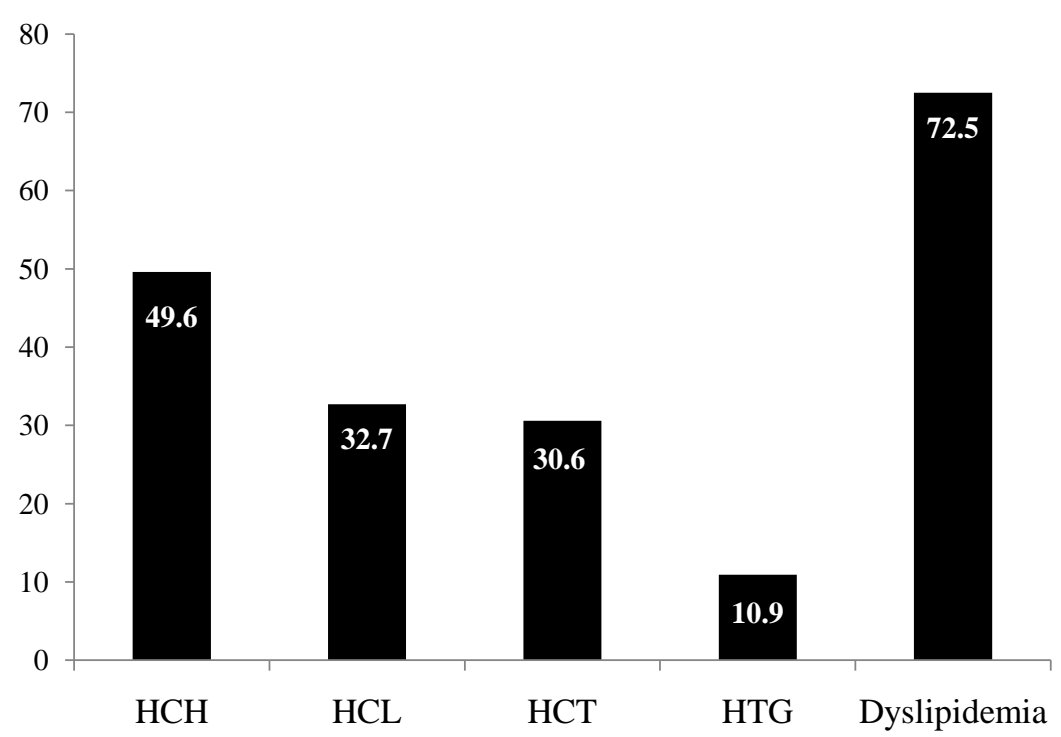

Figure 1. Frequencies of dyslipidemia at the Ambulatory Treatment Center of the Sylvanus Olympio University Hospital Lome [HCH: HDL hypocholesterolemia; HCL: LDL hypercholesterolemia; HCT: Total hypercholesterolemia; HTG: Hypertriglyceridaemia].

The median CT level was $182 \mathrm{mg} / \mathrm{dl}$ (IQR: 156 - 209). The average LDL-c level was $114 \mathrm{mg} / \mathrm{dl}( \pm 41)$. There was a significant difference between the average LDL-c rates of women and men $(p=0.011)$. Similarly, the difference in average LDL-c rates between first and second line patients was significant $(p=0.044)$ (Table 2). The median HDL-c level was $47 \mathrm{mg} / \mathrm{dl}$ (IQR: 42 - 55). The median triglyceride level was $81 \mathrm{mg} / \mathrm{dl}$ (IQR: $62 \mathrm{mg} / \mathrm{dl}-108 \mathrm{mg} / \mathrm{dl}$ ). The median atherosclerosis index was 3.75 (IQR: 2.93 - 4.45).

The study of the associations between dyslipidemia and the HAART molecules to which the subjects in our study were exposed revealed a statistically significant association between the NRTIs and the HCH (Table 2).

\subsection{Factors Associated with Dyslipidemia}

\section{Factors associated with HCT}

Our study suggests that BMI $(\mathrm{p}<0.01)$, history of HAART regimen substitution ( $\mathrm{p}<0.01), \mathrm{HCL}(\mathrm{p}<0.001)$, past treated tuberculosis $(\mathrm{p}=0.034), \mathrm{HCL}(\mathrm{p}<$ $0.01), \mathrm{HCH}(\mathrm{p}<0.01)$, was significantly associated to HCT. A CT/HDL-c ratio greater than 5 was also associated with a HCT $(\mathrm{p}<0.001)$ (Table 3$)$.

\section{Factors associated with $\mathrm{HCL}$}

The factors associated with HCL are BMI $(\mathrm{p}<0.01)$, past treated tuberculosis $(\mathrm{p}<0.01)$, history of HAART regimen substitution $(\mathrm{p}=0.011)$, HCT $(\mathrm{p}<0.001)$. A CT/HDL-c ratio was associated with HCL $(\mathrm{p}<0.001)$. (Table 4)

\section{Factors associated with $\mathrm{HCH}$}

The factors associated with $\mathrm{HCH}$ are BMI $(\mathrm{p}=0.037)$, HAART regimen substitution ( $\mathrm{p}=0.012)$, HCT $(\mathrm{p}<0.01)$, being on INRTs $(\mathrm{p}<0.01)$, abdominal obesity $(\mathrm{p}=0.029)$, history of weaned smoking $(\mathrm{p}=0.020)$ and CT/HDL-c ratio ( $\mathrm{p}$ $<0.001$ ) (Table 5). 
Table 2. Study of association between the types of dyslipidemia and the current HAART medications used by subjects.

\begin{tabular}{|c|c|c|c|c|c|}
\hline & HCT & HTG & HCL & $\mathrm{HCH}$ & Ratio CT/HDL-c $>5$ \\
\hline \multicolumn{6}{|l|}{ NRTIs } \\
\hline $\begin{array}{c}\text { TDF } \\
\mathrm{n}=257(\%)\end{array}$ & $76(29.6)$ & $26(10.1)$ & $81(31.5)$ & $134(52.1)$ & $39(15.2)$ \\
\hline $\begin{array}{c}\mathrm{AZT} \\
\mathrm{n}=8(\%)\end{array}$ & $4(50.0)$ & $2(25.0)$ & $4(50.0)$ & $4(50.0)$ & $1(12.5)$ \\
\hline $\begin{array}{c}\mathrm{ABC} \\
\mathrm{n}=19(\%)\end{array}$ & $7(36.8)$ & $3(15.8)$ & $8(42.1)$ & $3(15.8)$ & $2(10.5)$ \\
\hline $\mathrm{p}$-value & 0.388 & 0.322 & 0.365 & 0.009 & 0.845 \\
\hline \multicolumn{6}{|l|}{ NNRTIs } \\
\hline $\begin{array}{c}\mathrm{EFV} \\
\mathrm{n}=231(\%)\end{array}$ & $73(31.6)$ & $22(09.5)$ & $77(33.3)$ & $112(48.5)$ & $37(16.0)$ \\
\hline $\begin{array}{c}\text { NEV } \\
\mathrm{n}=4(\%)\end{array}$ & $2(50.0)$ & $2(50.0)$ & $2(50.0)$ & $1(25.0)$ & $0(00.0)$ \\
\hline $\mathrm{p}$-value & 0.382 & 0.053 & 0.412 & 0.340 & 0.502 \\
\hline \multicolumn{6}{|l|}{ IPs } \\
\hline $\begin{array}{c}\text { ATV } \\
\mathrm{n}=44(\%)\end{array}$ & $11(25.0)$ & $7(15.9)$ & $12(27.3)$ & $25(56.8)$ & $3(06.8)$ \\
\hline $\begin{array}{c}\text { LOP } \\
\mathrm{n}=5(\%)\end{array}$ & $1(20.0)$ & $0(00.0)$ & $2(40.0)$ & $3(60.0)$ & $2(40.0)$ \\
\hline p-value & 0.644 & 0.446 & 0.445 & 0.638 & 0.075 \\
\hline
\end{tabular}

HCT: Total Hypercholesterolemia; HTG: Hypertriglyceridemia; HCH: HDL Hypocholesterolemia; HCL: LDL Hypercholesterolemia; CT: Cholesterol Total; HDL-c: HDL Cholesterol; NNRTIs: Non-Nucleoside Reverse Transcriptase Inhibitors; NRTIs: Nucleoside Reverse Transcriptase Inhibitors; IPs: Protease Inhibitors; TDF: Tenofovir; AZT: Zidovudine; ABC: Abacavir; EFV: Efavirenz; NEV: Nevirapine; ATV: Atazanavir Boosted with Ritonavir; LOP: Lopinavir Boosted with Ritonavir.

Table 3. Factors associated to HCT in 284 HIV subjects on HAART medication.

\begin{tabular}{ccccc}
\hline & & \multicolumn{2}{c}{ HCT } & \\
\hline & Modalities & Yes & No & p-value \\
\hline BMI & & & & \\
& Normal & $30(10.6 \%)$ & $111(39.1 \%)$ & \\
& Pre-obesity & $34(12 \%)$ & $49(17.3 \%)$ & $<0.01$ \\
Obesity & $14(4.9 \%)$ & $19(6.7 \%)$ & \\
Past treated tuberculosis & Underweight & $9(3.2 \%)$ & $18(6.2 \%)$ & \\
& & & & \\
History of HAART regimen & No & $84(29.6 \%)$ & $175(61.6 \%)$ & $\mathbf{0 . 0 3 4}$ \\
substitution & Yes & $3(1.1 \%)$ & $22(7.7 \%)$ & \\
& & & & \\
& No & $26(9.1 \%)$ & $96(33.8 \%)$ & \\
& Yes & $61(21.5 \%)$ & $101(35.6 \%)$ & \\
\hline
\end{tabular}




\section{Continued}

\begin{tabular}{ccccc}
\hline HLC & & & & \\
& No & $9(3.2 \%)$ & $182(64.1 \%)$ & $<0.001$ \\
Yes & $78(27.5 \%)$ & $15(5.2 \%)$ & \\
HCH & & & & \\
& No & $54(19 \%)$ & $89(31.3 \%)$ & $<0.01$ \\
RATIO CT/HDL-c $\geq 5$ & Yes & $33(11.6 \%)$ & $108(38.1 \%)$ & \\
& & & & \\
& No & $57(20.1 \%)$ & $185(65.1 \%)$ & $<0.001$ \\
& Yes & $30(10.6 \%)$ & $12(4.2 \%)$ & \\
\hline
\end{tabular}

BMI: Body Mass Index; CT: Total Cholesterol; HAART: Highly Active Antiretroviral Therapy; HCH: HDL Hypocholesterolemia; HCT: Total Hypercholesterolemia; HDL-c: HDL Cholesterol; HLC: LDL Hypercholesterolemia.

Table 4. Factors associated to HCL in 284 subjects on HAART medication.

\begin{tabular}{|c|c|c|c|c|}
\hline & \multicolumn{4}{|c|}{ HLC } \\
\hline & Modalities & Yes & No & p-value \\
\hline \multicolumn{5}{|l|}{ BMI } \\
\hline & Normal & $31(10.9 \%)$ & $110(38.7 \%)$ & \multirow{4}{*}{$<0.01$} \\
\hline & Pre-obesity & $37(13 \%)$ & $46(16.2 \%)$ & \\
\hline & Obesity & $13(4.6 \%)$ & $20(7.1 \%)$ & \\
\hline & Underweight & $12(4.2 \%)$ & $15(5.3 \%)$ & \\
\hline \multicolumn{5}{|l|}{ Past treated tuberculosis } \\
\hline & No & $91(32 \%)$ & $168(59.2 \%)$ & \multirow[t]{2}{*}{$<0.01$} \\
\hline & Yes & $2(0.7 \%)$ & $23(8.1 \%)$ & \\
\hline \multicolumn{5}{|l|}{$\begin{array}{l}\text { History of HAART } \\
\text { regimen substitution }\end{array}$} \\
\hline & No & $30(10.6 \%)$ & $92(32.4 \%)$ & \multirow{2}{*}{0.011} \\
\hline & Yes & $63(22.2 \%)$ & $99(34.8 \%)$ & \\
\hline \multicolumn{5}{|l|}{ HCT } \\
\hline & No & $15(5.3 \%)$ & $182(64.1 \%)$ & \multirow{2}{*}{$<0.001$} \\
\hline & Yes & $78(27.5 \%)$ & $9(3.1 \%)$ & \\
\hline \multicolumn{5}{|l|}{ Ratio CT/HDL-c $\geq 5$} \\
\hline & No & $58(20.4 \%)$ & $184(64.8 \%)$ & \multirow{2}{*}{$<0.001$} \\
\hline & Yes & $35(12.3 \%)$ & $7(2.5 \%)$ & \\
\hline
\end{tabular}

BMI: Body Mass Index; CT: Total Cholesterol; HAART: Highly Active Antiretroviral Therapy; HCT: Total Hypercholesterolemia; HDL-c: HDL Cholesterol; HLC: LDL Hypercholesterolemia.

\section{Factors associated with HTG}

Our study did not identify any factors significantly associated with the occurrence of HTG (Table 6). 
Table 5. Factors associated to HCH in 284 HIV subjects on HAART medication.

\begin{tabular}{|c|c|c|c|c|}
\hline & \multicolumn{4}{|c|}{$\mathrm{HCH}$} \\
\hline & Modalities & Yes & No & p-value \\
\hline \multicolumn{5}{|l|}{ BMI } \\
\hline & Normal & $79(27.8 \%)$ & $62(21.8 \%)$ & \multirow{4}{*}{0.037} \\
\hline & Pre-obesity & $34(12 \%)$ & $49(17.3 \%)$ & \\
\hline & Obesity & 19 (6.7\%) & $14(4.9 \%)$ & \\
\hline & Underweight & $9(3.2 \%)$ & $18(6.3 \%)$ & \\
\hline \multicolumn{5}{|l|}{$\begin{array}{l}\text { History of HAART } \\
\text { regimen substitution }\end{array}$} \\
\hline & No & $51(18.0 \%)$ & $71(25.0 \%)$ & \multirow{2}{*}{0.012} \\
\hline & Yes & $70(24.6 \%)$ & $92(32.4 \%)$ & \\
\hline \multicolumn{5}{|l|}{ Past smoking } \\
\hline & No & $138(48.9 \%)$ & $135(47.9 \%)$ & \multirow{2}{*}{0.020} \\
\hline & Yes & $1(0.4 \%)$ & $8(2.8 \%)$ & \\
\hline \multicolumn{5}{|l|}{ Ratio CT/HDL-c $\geq 5$} \\
\hline & No & $107(37.7 \%)$ & $135(47.5 \%)$ & \multirow{2}{*}{$<0.001$} \\
\hline & Yes & $34(12 \%)$ & $8(2.8 \%)$ & \\
\hline \multicolumn{5}{|l|}{ Abdominal obesity } \\
\hline & No & $30(17.4 \%)$ & $46(26.7 \%)$ & \multirow{2}{*}{0.029} \\
\hline & Yes & $54(31.4 \%)$ & $42(24.4 \%)$ & \\
\hline \multicolumn{5}{|l|}{ NRTIs } \\
\hline & TDF & $134(47.2 \%)$ & $123(43.3 \%)$ & \multirow{3}{*}{$<0.01$} \\
\hline & $\mathrm{ABC}$ & $4(1.4 \%)$ & $4(1.4 \%)$ & \\
\hline & $\mathrm{AZT}$ & $3(1.1 \%)$ & $16(5.6 \%)$ & \\
\hline \multicolumn{5}{|l|}{ HCT } \\
\hline & No & $108(38.0 \%)$ & $89(31.3 \%)$ & \multirow{2}{*}{$<0.01$} \\
\hline & Yes & $33(11.6 \%)$ & 54 (19.1\%) & \\
\hline
\end{tabular}

ABC: Abacavir; AZT: Zidovudine; BMI: Body Mass Index; HAART: Highly Active Antiretroviral Therapy; HCH: HDL Hypocholesterolemia; HCT: Total Hypercholestérolemia; HDL-c: HDL Cholesterol; NRTIs: Nucleoside Reverse Transcriptase Inhibitors; TDF: Tenofovir.

Table 6. Factors associated to HTG in 284 HIV subjects on HAART medication.

\begin{tabular}{|c|c|c|c|c|}
\hline & \multicolumn{3}{|c|}{ HTG } & \multirow{2}{*}{$\mathrm{p}$-value } \\
\hline & & Yes & No & \\
\hline \multicolumn{5}{|l|}{ BMI } \\
\hline & Normal & $16(5.6 \%)$ & $125(44.0 \%)$ & \\
\hline & Pre-obesity & $11(3.9 \%)$ & $72(25.4 \%)$ & \\
\hline & Obesity & $3(1.1 \%)$ & $30(10.6 \%)$ & \\
\hline & Underweight & $1(0.4 \%)$ & $26(9.2 \%)$ & 0.562 \\
\hline
\end{tabular}




\section{Continued}

\begin{tabular}{ccccc}
\hline Past treated tuberculosis & & & & \\
& No & $29(10.2 \%)$ & $230(81 \%)$ & 0.469 \\
Hes & $2(0.7 \%)$ & $23(8.1 \%)$ & \\
$\begin{array}{c}\text { Hegimen substitution } \\
\text { ref HAART }\end{array}$ & & & & \\
& No & $9(3.2 \%)$ & $113(39.8 \%)$ & 0.069 \\
Past smoking & Yes & $22(7.7 \%)$ & $140(49.3 \%)$ & 0.358 \\
& No & $30(10.6 \%)$ & $243(86.2 \%)$ & \\
Ybdominal obesity & & $0(0.0 \%)$ & $9(3.2 \%)$ & \\
& Nes & $9(5.2 \%)$ & $67(39.0 \%)$ & 0.600 \\
& Yes & $9(5.2 \%)$ & $87(50.6 \%)$ & \\
\hline
\end{tabular}

BMI: Body Mass Index; HAART: Highly Active Antiretroviral Therapy; HTG: Hypertriglyceridemia.

\section{Discussion}

The purpose of our study was to evaluate the prevalence of dyslipidemia in PLWHIV subject on HAART at CTA, CHU-SO Lomé. The pre-therapeutic check-up that is requested of patients before initiation in our context does not require a lipid check-up to assess dyslipidemia in newly diagnosed HIV-positive patients before HAART begins. It was therefore impossible for us to profile dyslipidemia in patients before HAART is initiated. Indeed, it is not excluded that some patients may develop dyslipidemia before HAART is initiated according to the chronic inflammation due to the HIV or according to the genetic predispositions. However, our study allowed us to highlight an overall prevalence of dyslipidemia at $72.5 \%$. This result is similar to those reported in Cameroon and Tanzania [9] [10] but lower than the $82.3 \%$ reported in southern Ethiopia [6].

The prevalence of different dyslipidemia in our study was $49.6 \%, 32.7 \%, 30.6 \%$ and $10.9 \%$ respectively for HCH, HCL, HCT, and HTG. The CT/HDL ratio indicated a high risk of atherosclerosis in $14.8 \%$.

Our prevalence of HCT is similar to that reported in Cameroon by Bekolo et al. [9]. Nevertheless, other authors have achieved higher rates of $41 \%$ according to a study conducted in Togo by Djibril et al. [11] while in Uganda Buchacz et al. reported a $10 \%$ lower prevalence [12].

The prevalence of HTG observed in our study is lower than data reported by other authors who give a prevalence of HTG ranging from $18.3 \%$ reported in Benin by Adebayo et al. [13] to 55.8\% reported in Ethiopia by Tadewos et al. [6]

We have achieved an HCL prevalence of $32.7 \%$. This prevalence is in line with the work of Bekolo et al. in Cameroon [9], de Tadewos et al. in Ethiopia [6], and Adebayo et al. in Benin [13], which reported 33.3\%, 33.6\% and 34.83\% respectively. However, Armstrong et al. in Tanzania found in their series a 12\% lower 
prevalence [10].

$\mathrm{HCH}$ was found in $49.6 \%$ of the subjects in our study. This result confirms the one reported by Ezra et al. in Ethiopia [14], de Bernal et al. [15] in Spain, and Buchaz et al. in Uganda [12]. Nevertheless, a lower prevalence of $18.4 \%$ was reported by Bekolo et al. [9] and a higher prevalence of $43.4 \%$ by Tadewos et al. [6].

Fourteen point eight percent of the patients in our sample had a CT/HDL ratio at high risk of atherosclerosis. This result is close to those observed in Cameroon [5] [9]. In Ethiopia, a 45.5\% higher rate of patients on HAART with a high risk of atherosclerosis has been reported [6].

$\mathrm{HCH}$ was the most common dyslipidemia in our series followed by HCL (Figure 1). There is high variability in the literature with respect to the forms of dyslipidemia that predominate in PLWHIV under HAART.

Some studies reported HTG and HCL as the most predominant dyslipidemia [7] [9] while for others it was HTG and $\mathrm{HCH}$ [16].

This variability in dyslipidemia in PLWHA under HAART could be explained by multiple factors, namely HIV-induced inflammatory stress, individual genetic susceptibilities such as sex, gender and ethnicity [17]. Studies have also shown that the metabolism of antiretroviral drugs plays an important role in the high variability between individuals exposed to the same antiretrovirals [18].

$75.4 \%$ of females were the most represented in our study. This is consistent with observations made in Cameroon [5] [9], Benin [13], Ethiopie [14] [16].

The age groups 30 to 39 and 40 to 49 were the most represented with $61.6 \%$, which is consistent with the results of Djibril et al. [11].

The median body mass index was in our series of $23.80 \mathrm{~kg} / \mathrm{m}^{2}$ (IQR: 21.05 27.05). This result is very close to the median reported in Tanzania [10]. 40.8\% of the subjects in our sample had a BMI greater than or equal to $25 \mathrm{~kg} / \mathrm{m}^{2}$, of which $29.2 \%$ were classified as overweight and $11.6 \%$ as obese. Our result is close to what was observed by Djibril et al. in Togo [11] who observed in its series $36 \%$ but higher than the $20.4 \%$ reported by Tadewo et al. in southern Ethiopia [6].

Abdominal obesity was present in $44.2 \%$. This result is similar to the one observed by Adébayo et al. who found in his series 51.23\% [13].

There was no significant difference in dyslipidemia frequencies depending on whether the patient was on an NNRTI-based or PI-based combination. Djibril et al. reached the same conclusion [11]. It should be noted that this result contrasts with the data in the literature, which largely describe dyslipidemia associated with protocols including PIs, just as it is also known that NNRTIs induce lipid disorders during HAART [19] [20] [21] [22].

$\mathrm{HCH}$ was the only dyslipidemia that showed a statistically significant difference in its frequencies compared to the different molecules used as NRTIs. Mitochondrial toxicity has been associated with NRTIs, particularly thymidine analogues (Zidovudine and Stavudine), particularly in the disruption of metabolic pathways leading to insulin resistance and dyslipidemia [23] [24]. 
Our study showed that history of HAART regimen substitution is associated with $\mathrm{HCT}, \mathrm{HCL}$ and $\mathrm{HCH}$. This result reinforces guidelines that highlight the multi-factorial nature of dyslipidemia in PLWHIV on HAART and warns that changing antiretroviral therapy per se may not produce the expected improvements in lipid parameters [25].

Our study has shown that BMI is associated to HCT. This result is in line with the results already observed by some African authors [6] [7] [9] [13]. Our study revealed that a past history of tuberculosis treated in PLWHIV on HAART was associated with HCT, HCL. Our result contrasts with that of Pefura et al. [7]. Although tuberculosis can lead to a decrease in the concentration of lipid fractions in infected PLWHIV, it has been shown that after treatment their concentration could significantly increase [26] [27]. We did not find in our study an association between age, sex, CD4 count, duration of HAART, initial clinical stage and HCT unlike other authors [5] [6] [7].

HTG did not show in our study an association with the independent variables tested. Bekolo et al. and Pefura et al. in Cameroon found the same [7] [9]. In contrast, for Dickson et al., in Cameroon, HTG was associated with obesity and the duration of HAART [5] while for Armstrong et al. in Tanzania it was inversely associated with $\mathrm{CD} 4$, at the clinical stage, at existence of anemia and age [10].

HCL was associated with BMI. This result is in line with the results of Pefura, Dickson, Armstrong, Adebayo [5] [7] [10] [13]. HCT is associated to HCL. This indicates a predisposition in PLWHIV to develop atheroma plaques and therefore a high susceptibility to cardiovascular events. This trend is confirmed by the association between HCL and a CT/HDL ratio greater than 5 . We found that BMI was associated with $\mathrm{HCH}$. Adebayo achieved the same result as Armstrong [10] [13].

Beyond the undernutrition that can accompany HIV infection and explain $\mathrm{HCH}$, many studies argue in favor of a disturbed HDL-c metabolism in PLWHIV compared to uninfected subjects.

This may explain the low level of HDL-c frequently observed in PLWHIV [28]. After initiation of HAART, lipid levels return to normal levels and then increase well beyond pre-seroconversion levels except for HDL-c which persist at low levels [29] [30].

HCT was associated with $\mathrm{HCH}$. HDL-c being a protective factor, this result indicates in PLWHIV a higher risk of atherosclerosis, confirming the data in the literature that the incidence of cardiovascular events may be higher in PLWHIV than in HIV-negative subjects.

In our study, being female increased the risk of $\mathrm{HCH}$. This result contrasts with the findings of Armstrong et al. who found no association of $\mathrm{HCH}$ by gender [10]. Abdominal obesity $(\mathrm{p}=0.029)$ was in our series associated with $\mathrm{HCH}$. Obesity is closely linked to hypertension, diabetes, and dyslipidemia. Abdominal obesity and $\mathrm{HCH}$ fall within the definition of metabolic syndrome. Obesity is an independent risk factor for cardiovascular disease and is associated 
with a high risk of mortality [31].

Smoking was in our study associated with $\mathrm{HCH}$. This is consistent with data in the literature that have shown an association between smoking and $\mathrm{HCH}$ and how smoking cessation contributes to an increase in HDL-c [32] [33].

Other risk factors associated with $\mathrm{HCH}$ such as age, $\mathrm{CD} 4$ count, viral load, HTG reported in some studies were not identified in our study [10] [15].

Our study showed that HCT, HCH and HCL significantly increased the risk of atherosclerosis in PLWHIV on HAART because they were associated with a $\mathrm{CT} / \mathrm{HDL}$ ratio greater than 5 and therefore an increased risk of cardiovascular events. The international D:A:D (Data collection on adverse events of anti-HIV drugs) study showed a relative annual increase of $26 \%$ in the rate of myocardial infarction in patients exposed to HAART compared to the incidence in HIV patients not exposed to HAART [34].

\section{Conclusions}

Our study showed a high prevalence of dyslipidemia in patients receiving antiretroviral treatments at CTA, indicating a high risk for these patients to have cardiovascular events that could shorten their life expectancy.

Therefore, emphasis should be placed on screening for dyslipidemia for its care not only during the follow-up of patients on antiretrovirals but also before initiation of HAART.

\section{Conflicts of Interest}

We announce that we have no competing interests.

\section{References}

[1] Global HIV \& AIDS Statistics-2018 Fact Sheet. http://www.unaids.org/en/resources/fact-sheet

[2] Feeney, E.R. and Mallon, P.W.G. (2011) HIV and HAART-Associated Dyslipidemia. The Open Cardiovascular Medicine Journal, 5, 49-63. https://doi.org/10.2174/1874192401105010049

[3] Bamba, V. and Rader, D.J. (2007) Obesity and Atherogenic Dyslipidemia. Gastroenterology, 132, 2181-2190. https://doi.org/10.1053/j.gastro.2007.03.056

[4] Triant, V.A., Lee, H., Hadigan, C. and Grinspoon, S.K. (2007) Increased Acute Myocardial Infarction Rates and Cardiovascular Risk Factors among Patients with Human Immunodeficiency Virus Disease. The Journal of Clinical Endocrinology \& Metabolism, 92, 2506-2512. https://doi.org/10.1210/jc.2006-2190

[5] Nsagha, D.S., Weledji, E.P., Assob, N.J.C., Njunda, L.A., Tanue, E.A., kibu, O.D., et al. (2015) Highly Active Antiretroviral Therapy and Dyslipidemia in People Living with HIV/AIDS in Fako Division, South West Region of Cameroon. BMC Cardiovascular Disorders, 15, 95. https://doi.org/10.1186/s12872-015-0090-5

[6] Tadewos, A., Addis, Z., Ambachew, H. and Banerjee, S. (2012) Prevalence of Dyslipidemia among HIV-Infected Patients Using First-Line Highly Active Antiretroviral Therapy in Southern Ethiopia: A Cross-Sectional Comparative Group Study. AIDS Research and Therapy, 9, 31. https://doi.org/10.1186/1742-6405-9-31 
[7] Pefura Yone, E.W., Betyoumin, A.F., Kengne, A.P., Kaze Folefack, F.J. and Ngogang, J. (2011) First-Line Antiretroviral Therapy and Dyslipidemia in People Living with HIV-1 in Cameroon: A Cross-Sectional Study. AIDS Research and Therapy, 8 , 33. https://doi.org/10.1186/1742-6405-8-33

[8] Togo. https://www.unaids.org/fr/regionscountries/countries/togo

[9] Bekolo, C.E., Nguena, M.B., Ewane, L., Bekoule, P.S. and Kollo, B. (2014) The Lipid Profile of HIV-Infected Patients Receiving Antiretroviral Therapy in a rural Cameroonian Population. BMC Public Health, 14, 236. https://doi.org/10.1186/1471-2458-14-236

[10] Armstrong, C., Liu, E., Grinspoon, S., Okuma, J., Spiegelman, D., Guerino, C., et al. (2011) Dyslipidemia in an HIV-Positive, Antiretroviral Treatment-Naïve Population in Dar es Salaam, Tanzania. Journal of Acquired Immune Deficiency Syndromes, 57, 141-145. https://doi.org/10.1097/QAI.0b013e318219a3d1

[11] Djibril, M.A., Balaka, A., Djagodou, K., Tchamdja, T., Bagny, A., Bougoulga, O., et al. (2012) Les dyslipidemies et antiretroviraux chez les personnes vivant avec le VIH dans le service de medecine interne au Chu-Tokoin de Lome. Journal de la Recherche Scientifique de I Université de Lomé, 14, 45-49.

[12] Buchacz, K., Weidle, P.J., Moore, D., Were, W., Mermin, J., Downing, R., et al. (2008) Changes in Lipid Profile over 24 Months among Adults on First-Line Highly Active Antiretroviral Therapy in the Home-Based AIDS Care Program in Rural Uganda. Journal of Acquired Immune Deficiency Syndromes, 47, 304-311. https://doi.org/10.1097/QAI.0b013e31815e7453

[13] Adébayo, A., Albert, D.C., Ericie, S., Angelo, A.C., Jules, G., Armand, W., et al. (2015) Prévalence, facteurs associés et prédisposant au syndrome métabolique chez les personnes vivants avec le VIH sous traitement antirétroviral à Porto-Novo en 2014. The Pan African Medical Journal, 22, 296. https://doi.org/10.11604/pamj.2015.22.296.7923

[14] Daniel Seifu, E.B. (2014) Lipid Profile Derangements among Human Immunodeficiency Virus Infected Adults Receiving First Line Anti-Retroviral Therapy in Tikur Anbesa Specialized Hospital, Addis Ababa, Ethiopia: Comparative Cross-Sectional Study. Journal of AIDS \& Clinical Research, 5, 328. https://doi.org/10.4172/2155-6113.1000328

[15] Bernal, E., Masiá, M., Padilla, S. and Gutiérrez, F. (2008) High-Density Lipoprotein Cholesterol in HIV-Infected Patients: Evidence for an Association with HIV-1 Viral Load, Antiretroviral Therapy Status, and Regimen Composition. AIDS Patient Care STDs, 22, 569-575. https://doi.org/10.1089/apc.2007.0186

[16] Abebe, M., Kinde, S., Belay, G., Gebreegziabxier, A., Challa, F., Gebeyehu, T., et al. (2014) Antiretroviral Treatment Associated Hyperglycemia and Dyslipidemia among HIV Infected Patients at Burayu Health Center, Addis Ababa, Ethiopia: A Cross-Sectional Comparative Study. BMC Research Notes, 7, 380. https://doi.org/10.1186/1756-0500-7-380

[17] Kumar, P.N., Rodriguez-French, A., et al. (2006) A Prospective, 96-Week Study of the Impact of Trizivir, Combivir/Nelfinavir, and Lamivudine/Stavudine/Nelfinavir on Lipids, Metabolic Parameters and Efficacy in Antiretroviral-Naive Patients: Effect of Sex and Ethnicity. HIV Medicine, 7, 85-98. https://onlinelibrary.wiley.com/doi/full/10.1111/j.1468-1293.2006.00346.x

[18] Tarr, P.E., Rotger, M. and Telenti, A. (2010) Dyslipidemia in HIV-Infected Individuals: From Pharmacogenetics to Pharmacogenomics. Pharmacogenomics, 11, 587-594. https://doi.org/10.2217/pgs.10.35 
[19] Grunfeld, C. (2010) Dyslipidemia and Its Treatment in HIV Infection. Vol. 18, Topics in HIV Medicine: A Publication of the International AIDS Society, USA, 112-118.

[20] Domingos, H., da Cunha, R.V., Paniago, A.M.M., Martins, D.M., Elkhoury, E.B. and de Souza, A.S. (2009) Metabolic Effects Associated to the Highly Active Antiretroviral Therapy (HAART) in AIDS Patients. Brazilian Journal of Infectious Diseases, 13, 130-136. https://doi.org/10.1590/S1413-86702009000200012

[21] Heath, K.V., Chan, K.J., Singer, J., O’Shaughnessy, M.V., Montaner, J.S.G. and Hogg, R.S. (2002) Incidence of Morphological and Lipid Abnormalities: Gender and Treatment Differentials after Initiation of First Antiretroviral Therapy. International Journal of Epidemiology, 31, 1016-1020. https://doi.org/10.1093/ije/31.5.1016

[22] Young, J., Weber, R., Rickenbach, M., Furrer, H., Bernasconi, E., Hirschel, B., et al. (2005) Lipid Profiles for Antiretroviral-Naive Patients Starting PI- and NNRTI-Based Therapy in the Swiss HIV Cohort Study. Antiviral Therapy, 10, 585-591.

[23] Boothby, M., McGee, K.C., Tomlinson, J.W., Gathercole, L.L., McTernan, P.G., Shojaee-Moradie, F., et al. (2009) Adipocyte Differentiation, Mitochondrial Gene Expression and Fat Distribution: Differences between Zidovudine and Tenofovir after 6 Months. Antiviral Therapy, 14, 1089-1100. https://doi.org/10.3851/IMP1457

[24] Brown, T.T., Li, X., Cole, S.R., Kingsley, L.A., Palella, F.J., Riddler, S.A., et al. (2005) Cumulative Exposure to Nucleoside Analogue Reverse Transcriptase Inhibitors Is Associated with Insulin Resistance Markers in the Multicenter AIDS Cohort Study. AIDS, 19, 1375-1383. https://doi.org/10.1097/01.aids.0000181011.62385.91

[25] Dubé, M.P., Sprecher, D., Henry, W.K., Aberg, J.A., Torriani, F.J., Hodis, H.N., et al. (2000) Preliminary Guidelines for the Evaluation and Management of Dyslipidemia in Adults Infected with Human Immunodeficiency Virus and Receiving Antiretroviral Therapy: Recommendations of the Adult AIDS Clinical Trial Group Cardiovascular Disease Focus Group. Clinical Infectious Diseases, 31, 1216-1224. https://doi.org/10.1086/317429

[26] Padmapriyadarsini, C., Ramesh, K., Sekar, L., Ramachandran, G., Reddy, D., Narendran, G., et al. (2017) Factors Affecting High-Density Lipoprotein Cholesterol in HIV-Infected Patients on Nevirapine-Based Antiretroviral Therapy. Indian Journal of Medical Research, 145, 641.

[27] Gebremicael, G., Amare, Y., Challa, F., Gebreegziabxier, A., Medhin, G., Wolde, M., et al. (2017) Lipid Profile in Tuberculosis Patients with and without Human Immunodeficiency Virus Infection. International Journal of Chronic Diseases, 2017, Article ID: 3843291. https://doi.org/10.1155/2017/3843291

[28] Rose, H., Hoy, J., Woolley, I., Tchoua, U., Bukrinsky, M., Dart, A., et al. (2008) HIV Infection and High Density Lipoprotein Metabolism. Atherosclerosis, 199, 79-86. https://doi.org/10.1016/j.atherosclerosis.2007.10.018

[29] Riddler, S.A., Li, X., Otvos, J., Post, W., Palella, F., Kingsley, L., et al. (2008) Antiretroviral Therapy Is Associated with an Atherogenic Lipoprotein Phenotype among HIV-1-Infected Men in the Multicenter AIDS Cohort Study. Journal of Acquired Immune Deficiency Syndromes, 48, 281-288. https://doi.org/10.1097/QAI.0b013e31817bbbf0

[30] Riddler, S.A., Li, X., Chu, H., Kingsley, L.A., Dobs, A., Evans, R., et al. (2007) Longitudinal Changes in Serum Lipids among HIV-Infected Men on Highly Active Antiretroviral Therapy. HIV Medicine, 8, 280-287.

https://doi.org/10.1111/j.1468-1293.2007.00470.x

[31] Pischon, T., Boeing, H., Hoffmann, K., Bergmann, M., Schulze, M.B., Overvad, K., 
et al. (2008) General and Abdominal Adiposity and Risk of Death in Europe. The New England Journal of Medicine, 359, 2105-2120.

https://doi.org/10.1056/NEJMoa0801891

[32] Criqui, M.H., Wallace, R.B., Heiss, G., Mishkel, M., Schonfeld, G. and Jones, G.T. (1980) Cigarette Smoking and Plasma High-Density Lipoprotein Cholesterol. The Lipid Research Clinics Program Prevalence Study. Circulation, 62, IV70-IV76.

[33] Batić-Mujanović, O., Zildzić, M., Beganlić, A. and Kusljugić, Z. (2006) The Effect of Cigarette Smoking on HDL-Cholesterol Level. Medical Archives, 60, 90-92.

[34] The Data Collection on Adverse Events of Anti-HIV Drugs (DAD) Study Group (2003) Combination Antiretroviral Therapy and the Risk of Myocardial Infarction. The New England Journal of Medicine, 349, 1993-2003.

https://doi.org/10.1056/NEJMoa030218 